\title{
Effect of Posterior Dynamic Instrumentation on High-Intensity Zone in Lumbar Degenerative Disc Disease
}

\section{Posterior Dinamik Enstrümantasyonun Lomber Dejeneratif Disk Hastalı̆̆ında Görülen Yüksek Intensite Bölgesi Üzerine Etkisi}

\author{
Suat CANBAY ${ }^{1}$, Yaprak ATAKER ${ }^{2}$, Nazan CANBULAT ${ }^{3}$, Zeynep UNAL KABAOGLU ${ }^{4}$, Tunc OKTENOGLU ${ }^{5}$, \\ Mehdi SASANI ${ }^{5}$, Ali Fahir OZER ${ }^{6}$ \\ ${ }^{1}$ Dr. Abdurrabman Yurtaslan Oncology Training and Research Hospital, Neurosurgery Department, Ankara, Turkey \\ ${ }^{2}$ American Hospital, Department of Physical Medicine and Rehabilitation, Istanbul, Turkey \\ ${ }^{3}$ Koc University, School of Medicine, Department of Physical Medicine and Rehabilitation, Istanbul, Turkey \\ ${ }_{4}^{4}$ merican Hospital, Department of Radiology, Istanbul, Turkey \\ 5 American Hospital, Department of Neurosurgery, Istanbul, Turkey \\ ${ }^{6}$ Koc University, School of Medicine, Department of Neurosurgery, Istanbul, Turkey
}

Corresponding Author: Ali Fahir OZER / E-mail: alifahirozer@gmail.com

\begin{abstract}
AIM: To investigate high-intensity zone ( $\mathrm{HIZ}$ ) changes after lumbar posterior dynamic instrumentation.
\end{abstract}

MATERIAL and METHODS: Our study included 53 patients: 27 patients in group 1, 26 patients in group 2. All patients had one or two levels of degenerative disc disease with an HIZ confirmed by magnetic resonance imaging (MRI). Group 1 underwent one- or two-level dynamic lumbar posterior instrumentation. Group 2 was treated conservatively with an exercise program. Patients were evaluated using MRI, a numerical visual analog pain scale (VAS), and the Oswestry Disability Index (ODI) at baseline, at 1 year after surgery, and at final follow-up evaluation.

RESULTS: The mean duration of follow-up was 49.3 months in group 1 and 47.19 months in group 2. The baseline VAS and ODI scores were similar for both groups. The mean VAS score of group 1 was significantly improved at 1 year after surgery and at final follow-up. The mean ODI value was lower in group 1 than in group 2 at 1 year and at final follow-up. Pfirrmann grades in group 1 significantly differed at 1 year and at final follow-up but did not change in group 2. The number of HIZs significantly decreased in from baseline to 1 year and from baseline to final follow-up in group 1 but did not differ in group 2.

CONCLUSION: Dynamic lumbar stabilization systems are promising. Observations such as Pfirrmann grade improvements and disappearance of HIZs are concordant with improvements in VAS and ODI scores demonstrate that dynamic stabilization systems may provide an environment for regeneration.

KEYWORDS: High-intensity zone, Degenerative disc disease, Posterior dynamic instrumentation

öz

AMAÇ: Lomber posterior dinamik enstrümantasyonun yüksek intensite bölgesi (YiB)'ne etkisini incelemek.

YÖNTEM ve GEREÇLER: Çalışmaya 53 hasta dahil edildi; grup 1: 27 hasta, grup 2: 26 hasta. Bütün hastalarda Manyetik Rezonans Görüntüleme (MRG) ile tespit edilen bir veya iki seviyede YiB içeren dejeneratif disk hastalığı vardı. Birinci gruptaki hastalara bir veya iki seviyeli posterior dinamik enstrümantasyon yapıldı. İkinci grup egzersiz tedavisi ile takip edildi. Hastalar MRG, sayısal görsel ağrı skalası (GAS), Oswestry Özürlülük İndeksi (OÖi) ile tedavi öncesi, cerrahi sonrası 1. yıl ve geç dönemde değerlendirildi.

BULGULAR: Birinci grup ortalama 49,3 ay, ikinci grup ise 47,19 ay takip edildi. Başlangıç GAS ve OÖi ölçümleri her iki grupta benzerdi. Birinci grubun ortalama GAS skoru cerrahi sonrası 1. yıl ve geç dönemde belirgin olarak azaldı. Birinci grubun ortalama OÖi skoru 1. yıl ve geç takipte 2. Gruba göre daha düşük bulundu. Birinci grubun Pfirrmann evreleri 1. yıl ve geç takipte belirgin olarak değişirken, ikinci grupta değişiklik görülmedi. Birinci gruptaki YiB sayısı ilk değerlendirmeye göre 1. yıl ve geç takipte azalırken, ikinci grupta değişiklik gözlenmedi.

SONUÇ: Dinamik lomber stabilizasyon sistemleri ümit vericidir. Pfirrmann evrelerinde görülen gelişim, YiB'nin kaybolması ve bunların GAS ve OÖí skorlarındaki gelişmeler ile uyumlu olması dinamik stabilizasyon sistemlerinin rejenerasyon için uygun ortam sağlayabileceğini göstermektedir.

ANAHTAR SÖZCÜKLER: Yüksek intensite bölgesi, Dejeneratif disk hastalığı, Posterior dinamik enstrümantasyon 


\section{INTRODUCTION}

Lumbar disc degeneration, which results in segmental instability, is one of the major causes of chronic low back pain $(7,12)$. Degeneration begins with dehydration and a decrease in the tensile strength of the annulus fibrosus. Loss of disc height follows this cascade and may lead to segmental instability (20). Degenerative changes in the disc may affect the biomechanics of the spine. The clinical course of degeneration is defined as the dysfunctional phase, the unstable phase and, finally, the restabilization phase $(1,25)$.

Vertebral endplates, annuli fibrosi, vertebral periosteum, facet joints, and soft tissues may be sources of spine pain (4). Within a healthy disc, there is an equilibrium between matrix degradation and synthesis; an imbalance may cause functional impairment. Clefts and tears are the main hallmarks of disc degeneration $(6,13)$.

Many types of fusion approaches and dynamic screwrod stabilization techniques have been described for the treatment of degenerative disc disease $(17,19)$.

High-intensity zone (HIZ)s, which are observed using T2weighted magnetic resonance imaging (MRI) of lumbar discs, were defined by Aprill and Bogduk as areas having a high-intensity signal within the posterior annulus fibrosus and surrounded by a low-intensity signal, brighter than the signal in the nucleus pulposus. They also reported an $86 \%$ positive predictive value between the presence of HIZs and concordant pain with provocative discography (2). Stability of the lumbar spinal motion segment decreases in the presence of an HIZ (23). Changes in HIZ appearance after posterior dynamic instrumentation surgery have not been reported.

The aim of the study was to investigate HIZ changes after dynamic lumbar screw-rod fixation.

\section{MATERIAL and METHODS}

A retrospective study was designed to evaluate the HIZ changes following lumbar posterior dynamic stabilization. Totally 60 patients who underwent surgery with posterior dynamic instrumentation for the treatment of discogenic low back pain met the inclusion criteria for our study. Of them, 32 underwent surgery at center 1 between 2004 and 2008, and 28 underwent surgery at center 2 between 2007 and 2010 . Of the 60 patients, 27 patients ( 11 men and 16 women) who completed follow-up evaluations served as study participants. The mean age of patients was 38.7 years (range, 23-56 years).

After surgery, all patients were taught the principles of lower back protection, including correct posture and appropriate positioning for lying, standing, sitting, and lifting. Patients took part in a dynamic lumbar stabilization exercise program to strengthen their core muscles starting at 12 weeks after surgery, taking care to stay within the pain-free limits of their range of motion.

The control group (group 2) consisted of 26 patients ( 8 men and 18 women) with a mean age of 40.35 years (range, 24-55 years). Group 2 patients had one or two levels of degenerative disc disease with an HIZ. Fifteen of those patients were from center 1, and the rest were from center 2. Group 2 was treated conservatively with short-term nonsteroidal anti-inflammatory drugs (NSAID). Principles of lower back protection were taught to all patients. After the subsidence of pain, the same dynamic lumbar stabilization exercise program used for the post-surgical patients was used to strengthen core muscles for patients in the control group, with these patients also performing exercises within pain-free limits.

Compliance with the exercise program was checked by inviting patients to the rehabilitation department regularly. Patients in group 1 were scheduled for weekly appointments at the rehabilitation department from weeks 12 through 16 after surgery. During these visits, they gradually learned dynamic lumbar stabilization exercises. The exercise program was individualized, with pain-provoking exercises being excluded for each patient as needed. Patients were given a checklist to complete, showing whether they had performed the prescribed exercises, and were asked to show the checklists at every visit. Starting at 16 weeks after surgery, patients were examined monthly for 6 months. After 6 months, patients were seen every 3 months until the end of the second year.

All patients (groups 1 and 2) had one-or two-level degenerative disc disease with an HIZ confirmed by MRI. The disease in group 1 was unresponsive to a minimum of 6 months of conservative treatment, which consisted of oral medication (NSAIDs, pain medication), a physiotherapy program, and core-strengthening exercises. When conservative treatment failed, physicians suggested that patients undergo lumbar posterior dynamic instrumentation surgery to control the pain resulting from segmental instability due to degenerative disc disease. Patients who did not agree to undergo surgery composed the control group.

Study inclusion criteria were as follows: one- or two-level lumbar degenerative disc disease without radicular pain, age between 20 and 60 years, degenerative disc disease and the presence of an HIZ confirmed by MRI, and discogenic pain unresponsive to at least 6 months of conservative treatment.

Patients with previous spinal surgery at any level, multilevel degenerative disc disease (more than two levels), osteoporosis, degenerative spondylolisthesis, spinal stenosis, scoliosis, spinal tumors, or fracture due to previous trauma were excluded from the study.

Clinical evaluations in both centers were performed with MRI before and after surgery. Patients were informed about the planned follow-up MRI evaluations at the beginning of the study. In group 1, MRI evaluations were performed preoperatively, at 1 year after surgery, and at a late postsurgical follow-up visit (after a minimum of 2 years). Pain was graded with a numerical visual analog scale (VAS), and patients' disability due to low back pain was evaluated with the Oswestry Disability Index (ODI) at initial evaluation, preoperatively ( 6 months after initial evaluation), at 3 months 
after surgery, at 1 year after surgery, and at a late postsurgical follow-up visit (at a minimum of 2 years). In group 2, MRI evaluations were performed at the initial visit, at 1 year, and at a late follow-up visit (at a minimum of 2 years). Pain was graded with a VAS, and patients' disability due to low back pain was evaluated with the ODI at the initial evaluation, at 6 months, at 1 year, and at a late follow-up visit (at a minimum of 2 years).

The ODI is a patient-completed questionnaire that measures function in activities of daily living. It involves 10 questions grading the level of discomfort associated with pain, self-care, lifting, walking, sitting, standing, sleep, sexual activity, social life, and traveling (11).

\section{Surgical Procedure}

All operations were performed with the patient under general anesthesia and in a neutral prone position. A midline incision was performed. After the lumbar aponeurosis was opened, the paravertebral muscles were dissected bilaterally, with capsular ligaments being preserved from surgical damage. Dynamic screws (cosmicMIA system, Ulrich Medical, Ulm, Germany, and Medikon Co. Ltd., Ankara, Turkey) were placed on the lateral sides of the facet joints under fluoroscopic visualization. The screws were connected to each other with rods.

\section{Imaging Technique}

Imaging was performed using several 1.5-Tesla MRI systems. The imaging parameters varied slightly, depending on the system. All examinations included sagittal fast spin-echo $\mathrm{T}_{2}$-weighted MRI (4000-4500/110-125/2-3 [time between pulses/echo time/number of excitations]) and sagittal $\mathrm{T}_{1}$ weighted MRI (520-640/10/3). Both $\mathrm{T}_{1}$ - and $\mathrm{T}_{2}$-weighted imaging had the following parameters: section thickness, 4.0 $\mathrm{mm}$; section gap, $0.4 \mathrm{~mm}$; field of view, $300 \mathrm{~mm}$.

\section{Data Interpretation}

Findings were analyzed by one radiologist (INITIALS REMOVED FOR BLINDED REVIEW). An annular tear was defined as a focal area of hyperintensity on $\mathrm{T}_{2}$-weighted images (2). The presence or absence of annular tears was noted for each examination. The persistence or resolution of findings in serial examinations was noted at each level. Intervertebral disc grading was performed using the Pfirrmann classification (21).

\section{Statistical Analysis}

The statistical analyses were performed using NCSS statistical software (2007 version; NCSS, LLC, Kaysville, UT,
USA). In addition to the descriptive statistical methods (average, standard deviation), a repeated measures analysis of variance was used to analyze the same parameter under different conditions (between groups). The Newman-Keuls multiple comparison test was used to compare subgroups, and the unpaired $t$-test was used to compare two groups. The chi-square test and Fisher's exact test were used to compare qualitative data, and the McNemar test was used for the repetitive assessment of qualitative data. A twotailed probability value of $<0.05$ was considered statistically significant.

\section{RESULTS}

Eleven men and 16 women with a mean age of $38.7 \pm 8.39$ years formed the study group (group 1). The control group (group 2) included 26 patients ( 8 men and 18 women) with a mean age of $40.35 \pm 8.99$ years. The mean duration of followup was $49.3 \pm 18.35$ months for group 1 and $47.19 \pm 16.43$ months for group 2. Age, sex, and follow-up duration did not significantly differ between the groups $(P=0.495,0.449$, and 0.662 , respectively) (Table I).

Because 12 patients in group 1 had two-level disc surgery, a total of 39 levels of lumbar segments were evaluated. Five patients in group 2 had two levels of disc degeneration, and a total of 31 levels of lumbar discs were evaluated in group 2.

The initial mean VAS scores were not significantly different between the two groups ( $p=0.323$ ), and they did not change significantly for those patients who had conservative treatment only. Patients in group 1 had only a slight decrease in VAS score (a decrease in mean scores from 7.78 to 7.74) after 6 months of conservative treatment. Patients who had still pain but slight improvement (mean VAS score decreased from 7.54 to 7.31) after 6 months of exercise did not agree to undergo surgery, and they composed the control group (group 2).VAS scores after 6 months of conservative treatment were not significantly different between the two groups $(P=$ 0.063).

The VAS scores significantly differed between the groups after surgery at both at the 1-year and final follow-up examinations ( $p=0.0001$ and $p=0.0001$, respectively), however (Table II). The VAS scores in group 1 at initial evaluation and after 6 months of conservative treatment but before surgery did not change significantly ( $p=0.574$ ). The mean group 1 VAS scores decreased significantly between the preoperative evaluation and the evaluation at 3 months after surgery $(P=$ 0.0001 ), between the preoperative evaluation and the 1-year

Table I: Demographic Data

\begin{tabular}{|l|r|r|r|}
\hline & Group 1 & Group 2 & p \\
\hline Age (year) & $38.7 \pm 8.39$ & $40.35 \pm 8.99$ & 0.495 \\
\hline Number of male patients (\%) & $11(40.70 \%)$ & $8(30.80 \%)$ & 0.449 \\
\hline Number of female patients (\%) & $16(59.30 \%)$ & $18(69.20 \%)$ & 0.662 \\
\hline Duration of follow-up (months) & $49.3 \pm 18.35$ & $47.19 \pm 16.43$ & \\
\hline
\end{tabular}


follow-up evaluation ( $p=0.0001$ ), between the preoperative evaluation and the final follow-up evaluation ( $p=0.0001$ ), between the 3-month postoperative evaluation and the 1-year follow-up evaluation ( $p=0.006$ ), and between the 1 -year and the final follow-up evaluation $(p=0.001)$. The group's scores at initial evaluation and after 6 months of conservative treatment did not change significantly $(p=$ 0.327). The group's scores significantly decreased between the initial evaluation and 1 year $(p=0.0001)$, between initial evaluation and final follow-up evaluation ( $p=0.0001)$, and between 1 year and final follow-up evaluation $(p=0.0001)$. In group 1, pain subsided gradually within 3 to 12 weeks after surgery and the mean VAS score decreased to 2.04 by 12 weeks. The decrease in mean VAS score in group 1 by the 3-month postoperative evaluation was statistically significant ( $p=0.0001)$. Immediately after that point, group members began participating in the dynamic lumbar stabilization exercise program.

The ODI values at the initial evaluation did not significantly differ between the groups ( $p=0.257)$, but they improved over time. The mean initial ODI value for group 1 was 76.59. This value decreased to 75.19 after 6 months of conservative treatment $(p=0.07)$. Three months after surgery, ODI values improved to 12.52 in group $1(p=0.0001)$. The group's ODI values significantly differed at the preoperative evaluation, 3-month evaluation, 1-year evaluation, and final followup evaluation ( $p=0.0001$ ) (Table II), and they significantly decreased between preoperative evaluation and evaluation 3 months after surgery ( $p=0.0001)$, between preoperative evaluation and evaluation 1 year after surgery $(p=0.0001)$, between preoperative evaluation and final follow-up evaluation ( $p=0.0001)$, between the 3-month evaluation and the 1-year follow-up evaluation $(p=0.014)$, and between the
1 -year and final follow-up evaluations $(p=0.001)$. The ODI values for group 2 did not change significantly $(p=0.098)$ from initial evaluation to after 6 months of conservative treatment. Group 2 ODI values significantly differed from initial evaluation to 1-year evaluation to final follow-up evaluation ( $p=0.0001$ ) (Table II). In addition, the group's ODI values significantly decreased between the initial evaluation and the 1-year evaluation ( $p=0.0001$ ), between the initial evaluation and the final follow-up evaluation ( $p=0.0001$ ), and between the 1-year and the final follow-up evaluations $(p=0.001)$. Finally, the group 1 ODI values were significantly lower than group 2 ODI values at 1 year $(p=0.0001)$ and final follow-up evaluations $(p=0.0001)$.

Pfirrmann grade distributions did not significantly differ between groups at the initial evaluation ( $p=0.662)$, 1-year evaluation ( $p=0.365)$, or final follow-up evaluation $(p=0.365)$, but they did change significantly over time in group 1 (Table III). Compared with the initial evaluation, group 1 Pfirrmann grade distribution changed significantly by 1 year $(p=0.046)$ and by the final follow-up evaluation ( $p=0.046$ ) (Table III). The Pfirmann grade 4 disc degeneration found at four levels in group 1 at initial follow-up evaluation improved to grade 3 at 1 year after surgery, but grade distributions did not change between the 1-year and final follow-up evaluations. Pfirrmann grade distribution for group 2 did not change during followup.

The number of HIZs in group 1 significantly decreased between the initial evaluation and the 1-year evaluation ( $p$ $=0.0001$ ) and between the initial evaluation and the final follow-up evaluation ( $p=0.0001)$. At the initial evaluation, $89.7 \%$ of lumbar segments (35 of 39 levels) in group 1 had an HIZ. This percentage decreased to $28.2 \%$ by 1 year (Figure

Table II: Comparison of VAS Scores and ODI Values at Initial Evaluation, 1-Year Evaluation, and Late Follow-Up

\begin{tabular}{|c|c|c|c|}
\hline Score/Value & Group 1 & Group 2 & $\mathbf{p}$ \\
\hline \multicolumn{4}{|l|}{ VAS } \\
\hline Initial & $7.78 \pm 0.89$ & $7.54 \pm 0.86$ & 0.383 \\
\hline Preoperative & $7.74 \pm 0.814$ & $7.31 \pm 0.84$ & 0.063 \\
\hline 3 months & $2.04 \pm 0.94$ & - & \\
\hline 1 year & $1.78 \pm 1.12^{*}$ & $4.92 \pm 0.98^{*}$ & 0.0001 \\
\hline Final follow-up & $1.37 \pm 0.88^{* \dagger}$ & $3.12 \pm 1.24^{* *}$ & 0.0001 \\
\hline$P$ value & 0.0001 & 0.0001 & \\
\hline \multicolumn{4}{|l|}{ ODI } \\
\hline Initial & $76.59 \pm 7.94$ & $74.31 \pm 6.44$ & 0.257 \\
\hline Preoperative & $75.19 \pm 7.75$ & $73.92 \pm 6.36$ & 0.518 \\
\hline 3 months & $12.52 \pm 5.64$ & - & \\
\hline 1 year & $12 \pm 5.95^{*}$ & $47.35 \pm 10.61^{*}$ & 0.0001 \\
\hline Final follow-up & $7.26 \pm 4.58^{* *}$ & $30.08 \pm 11.32^{* *}$ & 0.0001 \\
\hline$P$ value & 0.0001 & 0.0001 & \\
\hline
\end{tabular}

VAS multiple comparison group 1: ${ }^{*} p<0.0001{ }^{+} p<0.001$; group $2{ }^{* *} p<0.0001$. ODI multiple comparison group 1: ${ }^{*} p<0.0001$; group 2: ${ }^{* *} p<0.0001$. ODI, Oswestry Disability Index; VAS, visual analog scale. 
$1 \mathrm{~A}-\mathrm{C})$. However, the number of HIZs in group 1 did not differ between the 1-year examination and the final follow-up examination (Table IV).

In group 2, an HIZ was present in $87.09 \%$ of lumbar segments ( 27 of 31 levels) at the initial evaluation, and this finding did not change by either the 1-year evaluation or the final followup evaluation (Figure $2 \mathrm{~A}-\mathrm{C}$ ).

We did not observe infection, chronic inflammation, or segment loosening in our study group. In 2 cases, patients experienced pedicle screw breakage at 2 and 3 years after surgery. Paravertebral muscle fibrosis was detected in 1 patient. Three of our patients had disc herniation by 18,24 , and 72 months after instrumentation. Of those 3 patients, 2 had herniation at the adjacent segment and 1 had herniation two segments above the dynamic instrumentation. One of the patients with a neurological deficit who had herniation at the adjacent upper segment underwent surgery. Only microlumbar discectomy was performed in that patient because there was small-fragment fissure-type herniation as described by the Carragee classification (8). The other 2 patients who had radicular pain (1 in the adjacent segment, and the other 2 segments above the location of dynamic instrumentation) without neurological deficit were treated with oral medication and physical therapy.

Table III: Comparison of Pfirrmann Grades

\begin{tabular}{|c|c|c|c|}
\hline Pfirrmann grades & Group $1(\%)$ & Group $2(\%)$ & $\mathbf{p}$ \\
\hline \multicolumn{4}{|l|}{ Initial } \\
\hline 3 & $11(28.20)$ & $7(22.60)$ & \\
\hline 4 & $27(69.20)$ & $24(77.40)$ & \\
\hline 5 & $1(2.60)$ & $0(0.00)$ & 0.662 \\
\hline \multicolumn{4}{|l|}{1 year $^{*}$} \\
\hline 3 & $15(38.50)$ & $10(32.30)$ & \\
\hline 4 & $23(59.00)$ & $21(67.70)$ & \\
\hline 5 & $1(2.60)$ & $0(0.00)$ & 0.365 \\
\hline \multicolumn{4}{|l|}{ Final follow-up* } \\
\hline 3 & $15(38.50)$ & $10(32.30)$ & \\
\hline 4 & $23(59.00)$ & $21(67.70)$ & \\
\hline 5 & $1(2.60)$ & $0(0.00)$ & 0.365 \\
\hline
\end{tabular}

${ }^{*}$ Group 1 initial/first year and initial/final: $P=0.046$.
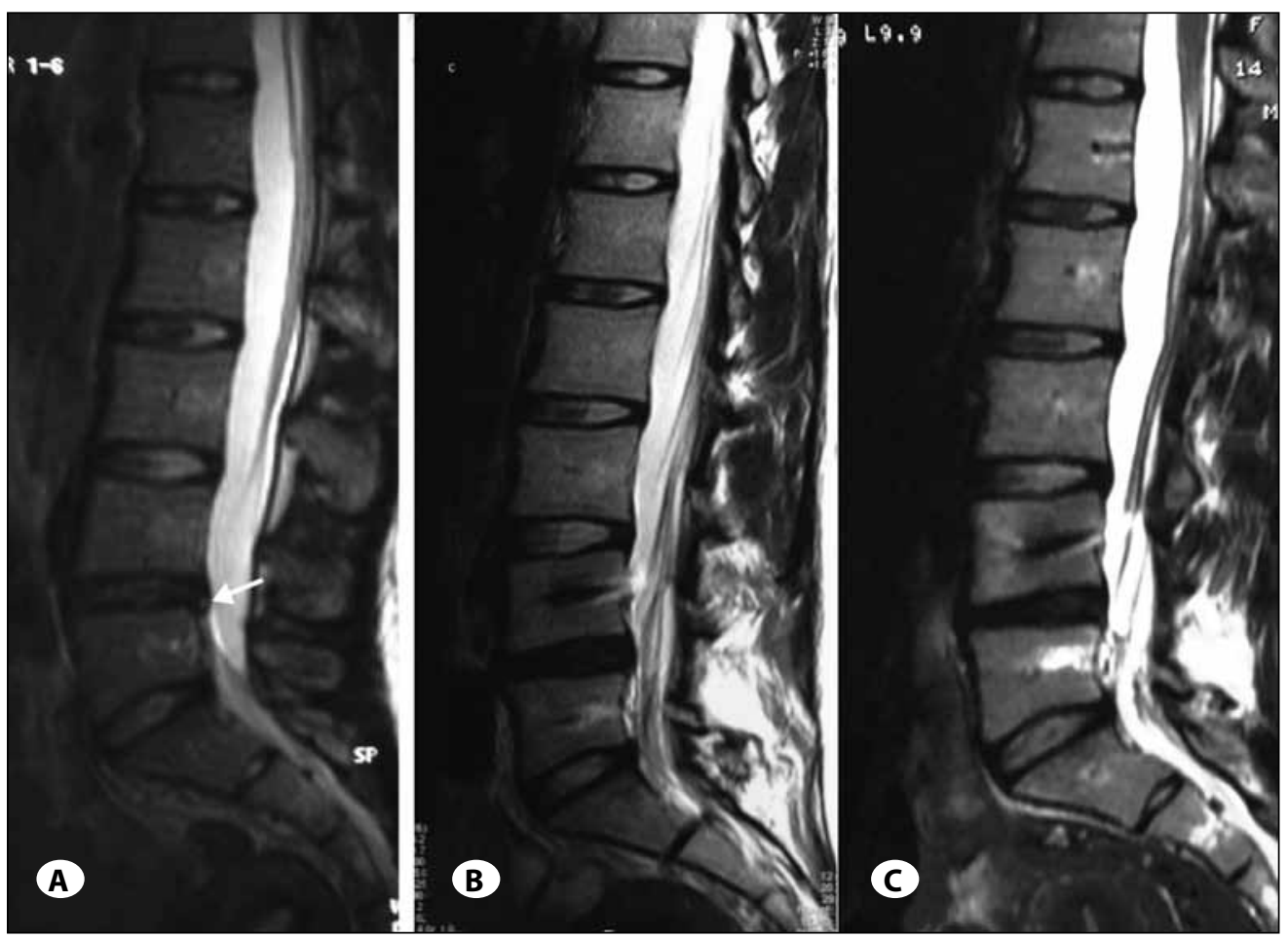

Figure 1: Sagittal magnetic resonance images for a single patient:

A) A preoperative image showing degenerative disc disease with a high-intensity zone (HIZ) at the L4-L5 level. B) A postoperative image showing disappearance of the HIZ at the L4-L5 level by the 1-year follow-up evaluation.

C) A postoperative image obtained at the final followup evaluation of the same patient. 


\section{DISCUSSION}

Fusion surgery was the previous gold standard treatment for degenerative conditions of the lumbar spine, and there are different approaches to spinal fusion. New technologies have been developed to stabilize the functional spinal unit because of the proven disadvantages of spinal fusion, including pseudoarthrosis, nonunion, instrumentation failure, restriction of the spinal range of motion, adjacent segment disease, infection, and donor site pain $(5,14,18)$. The newly developed dynamic spinal stabilization systems have aimed to stabilize the operated segment while preserving motion $(3,26)$.

Our study revealed statistically significant improvement in VAS scores and ODI values both in the operated group and the control group. The improvement in the operated group was statistically significantly better than the control group.

Table IV: Change in HIZ for Group 1

\begin{tabular}{|l|c|c|c|}
\hline HIz & $\mathbf{n}$ & $\%$ & $\mathbf{p}$ \\
\hline Initial & & & \\
\hline Absent & 4 & 10.3 & \\
\hline Present & 35 & 89.7 & \\
\hline 1 year & & & 0.0001 \\
\hline Absent & 28 & 71.8 & \\
\hline Present & 11 & 28.2 & \\
\hline Final follow-up & & & 0.0001 \\
\hline Absent & 28 & 71.8 & \\
\hline Present & 11 & 28.2 & \\
\hline
\end{tabular}

HIZ, high-intensity zone.
In the operated group, the mean VAS score improved from 7.74 to 1.37 and the mean ODI value improved from $75.19 \%$ to $7.26 \%$ at final follow-up evaluation. Reyes-Sánchez et al. in their prospective study, reported clinical and radiological data for patients treated with microsurgical decompression and stabilization with the AccuFlex dynamic rod device (22). A total of 20 consecutive patients at 2 years of follow-up had a mean VAS score for back pain that improved from 7.9 to 2.8 and a mean ODI value that improved from $55 \%$ before surgery to $24 \%$ at final evaluation. Our results for final VAS scores and ODI values were concordant with those of the study by ReyesSánchez et al.

Similar to our study, Zagra et al. found significant improvements in pain and disability scores at a 1-year follow-up evaluation using a new lumbar dynamic stabilization system in patients with degenerative lumbar spine instability in a prospective study (27).

Schmidt et al. investigated the stiffness in motion segments with and without HIZs or radial tears of the annuli fibrosis in their human cadaveric study (23). They showed that the presence of an HIZ in the intervertebral disc was associated with reduced stiffness in the motion segments. The presence of an HIZ and subsequent instability may explain the pain felt by their patients.

Djurasovic et al. investigated which MRI findings in patients with degenerative disc disease predict clinical improvement after lumbar fusion, and they concluded that disc desiccation, disc contour, presence of an HIZ lesion, and the presence of Modic endplate changes did not correlate with 2-year outcomes (10). They found that only a narrow disc space height $(<5 \mathrm{~mm})$ correlated with clinical improvement. They suggested that many commonly used MRI findings are not
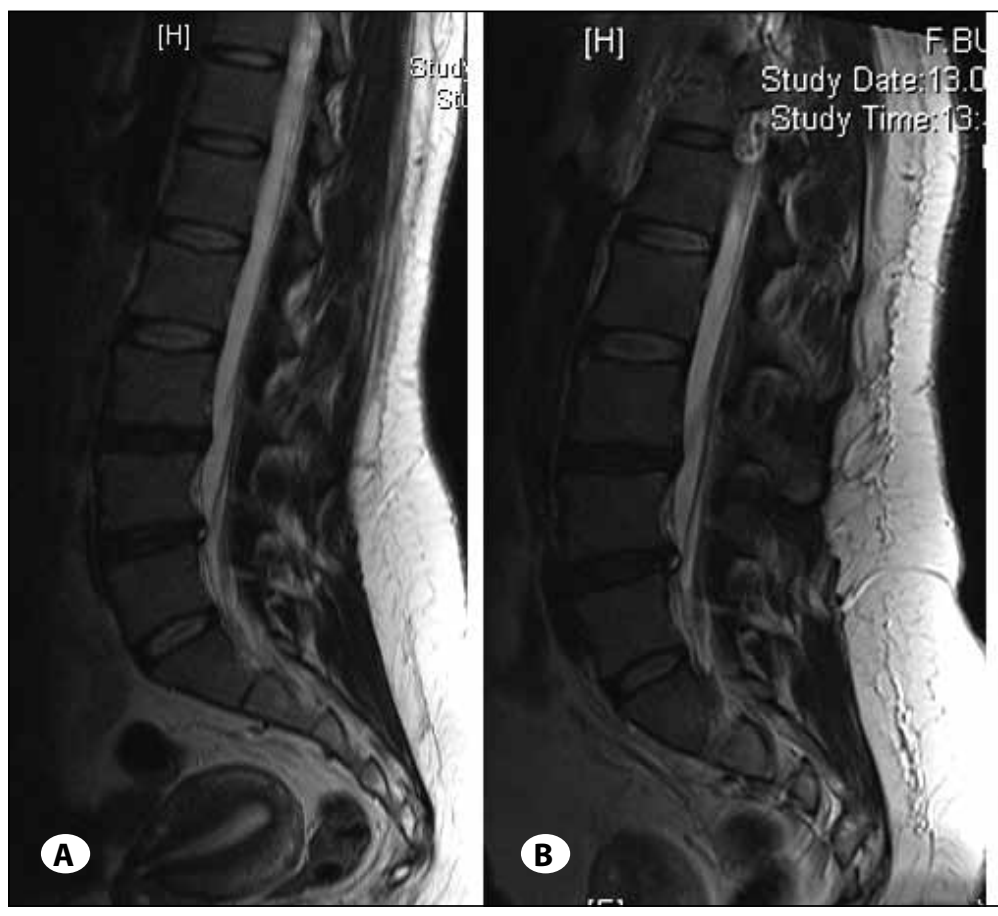

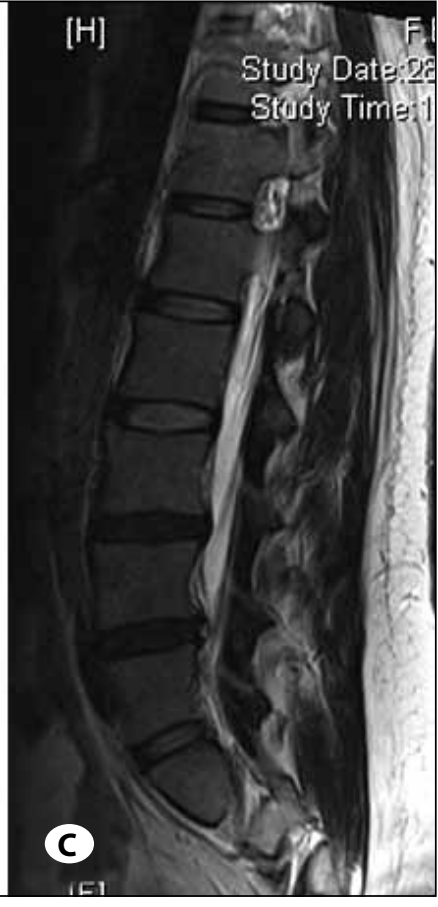

Figure 2: Magnetic resonance images for a different patient than in Figure 1 ; A) An image obtained at initial evaluation shows a highintensity zone (HIZ) at the L4-L5 level. Images obtained at B) 1-year follow-up evaluation and C) at the final follow-up evaluation show no change in the HIZ. 
reliable markers of improvement after lumbar fusion. They also suggested that disc desiccation or disc contour did not correlate with clinical improvement after fusion. They noted that desiccation is used as an indication for fusion in younger patient groups, especially if seen in combination with annular tears.

López et al., who investigated the clinical and radiological associations with lumbar discography in patients with chronic low back pain, concluded that presence of an HIZ on MRI is related to a higher rate of positive findings on discography (16). However, because of their study's small sample size, those findings are not statistically significant.

The patients in our study were young, and their pain can be explained by segmental instability due to degenerated discs and the presence of an HIZ. It is known that an HIZ may be present in patients who have no symptoms, but its presence increases the segmental instability of the degenerated segment $(9,16,23)$. The presence of an HIZ was not the only reason our patients underwent surgery; the main problem seemed to be the presence of degenerative discs and the resulting segmental instability. Also, disc disease in all of our patients was unresponsive to conservative treatment.

Kumar et al. revealed the efficacy of dynamic muscular stabilization techniques over conventional techniques in the rehabilitation of patients with chronic low back pain (15). The conventional techniques in their study involved ultrasound and short-wave diathermy in addition to lumbarstrengthening exercises. In our study, VAS scores and ODI values significantly improved in the control group, possibly because of the group's participation in the dynamic lumbar stabilization exercise program. In such programs, decreased back pain may be a result not only of restored muscle strength but also of improved balance, posture, position, and coordination.

After participating in a dynamic lumbar stabilization exercise program after surgery, our group 1 patients had significant improvements in their VAS scores and ODI values. When we compared groups 1 and 2, group 1 had better scores, which is likely due to the stabilization surgery performed prior to participation in dynamic lumbar stabilization exercises.

At 1 year after surgery, we observed a reversal of Pfirrmann grades from 4 to 3 at four levels in 4 different patients in group 1, and this improvement remained at the final followup examination. There was no change in Pfirrmann grades in any levels of disc degeneration in the control group. In their prospective study using various dynamic stabilization systems in the treatment of degenerative discopathy and instability of the lumbar spine, Zagra et al. showed a change in Pfirmann grade from 4 to 3 in 8 of 32 patients at an average of 12 months of follow-up (27). Similarly, in their study, Reyes-Sánchez et al. reported research on 20 patients who underwent posterior dynamic stabilization of the lumbar spine and were monitored for 2 years (22). Three of those patients had a change in Pfirmann grade from 3 to 2 . In 3 other patients in that study, the Pfirrmann grade worsened, but those 3 patients had a rupture of the dynamic system that was used. Patients with intact systems showed disc rehydration.

Of the 27 patients in our group of patients who underwent surgery (group 1), three disc herniations that occurred at 18, 24 , and 72 months after surgery (two in an adjacent segment and one in 2 segments above the instrumented level) can be explained by loading of the adjacent segments of the dynamically stabilized part of the spine.

Even though dynamic instrumentation surgery was done instead of fusion surgery in our group 1 with the aim of preserving motion, dynamic instrumentation may also restrict physiological motion in the lumbar spine, which may in turn cause herniation at adjacent segments.

In our study, pedicle screws at one level had broken in two patients by 2 and 3 years after surgery. Because the patients did not have symptoms, no revision surgery was performed. The Pfirrmann grades for these two patients remained the same on follow-up MRI. This may be explained by the timing of the control MRI, which occurred near the time the pedicle screws broke.

The presence of an HIZ was a predominant finding at the initial evaluation in group 1 and an $\mathrm{HIZ}$ was observed in 35 of 39 levels (89.7\%). At 1 year after surgery, an $\mathrm{HIZ}$ was present in 11 of 39 levels (28.2\%), and that finding remained unchanged at the final follow-up examination. An HIZ was present in 27 of 31 levels (87.09\%) in the control group, and the HIZs did not disappear during the follow-up period. Disc rehydration and improvements in Pfirrmann grades may be a feature of dynamic stabilization systems, as explained by Schnake et al. and Reyes-Sánchez et al $(22,24)$.

\section{CONCLUSION}

Dynamic stabilization systems show promise in patients with degenerative disc disease. Although there is no direct evidence that these implants will lead to disc regeneration, observations such as Pfirrmann grade improvements and the disappearance of HIZs concordant with improvements in VAS scores and ODI values indicate that such systems may provide an environment for biological regeneration.

It is important to be aware that even though dynamic instrumentation surgery is performed instead of fusion surgery to preserve motion, instrumentation may restrict physiological motion in the lumbar spine in comparison with patients who patients who do not undergo instrumentation surgery, and this restriction may cause herniation at adjacent segments.

\section{REFERENCES}

1. Adams MA, Dolan P: Spine biomechanics. J Biomech 38:19721983, 2005

2. Aprill C, Bogduk N: High-intensity zone: A diagnostic sign of painful lumbar disc on magnetic resonance imaging. $\mathrm{Br} \mathrm{J}$ Radiology 65:361-369, 1992 
3. Beastall J, Karadimas E, Siddiqui M, Nicol M, Hughes J, Smith F, Wardlaw D: The Dynesys lumbar spinal stabilization system: A preliminary report on positional magnetic resonance imaging findings. Spine (Phila Pa 1976) 32:685-690, 2007

4. Bogduk N: The innervation of the lumbar spine. Spine (Phila Pa 1976) 8:286-293, 1983

5. Bono C, Lee C: Critical analysis of trends in fusion for degenerative disc disease over the past 20 years: Influence of technique on fusion rate and clinical outcome. Spine (Phila Pa 1976) 29:455-463, 2004

6. Buckwalter JA, Roughley PJ, Rosenberg LC: Age-related changes in cartilage proteoglycans: Quantitative electron microscopic studies. Microsc Res Tech 28:398-408, 1994

7. Butler D, Trafimow JH, Andersson GB, McNeill TW, Huckman MS: Discs degenerate before facets. Spine (Phila Pa 1976) 15;111-113, 1990

8. Carragee EJ, Han MY, Suen PW, Kim D: Clinical outcomes after lumbar discectomy for sciatica: The effects of fragment type and anular competence. J Bone Joint Surg Am 85A:102-108, 2003

9. Carragee EJ, Tanner CM, Khurana S, Hayward C, Welsh J, Date E, Truong T, Rossi M, Hagle C:The rates of false-positive lumbar discography in select patients without low back symptoms. Spine (Phila Pa 1976) 25:1373-1380, 2000

10. Djurasovic M, Carreon LY, Crawford CH 3rd, Zook JD, Bratcher KR, Glassman SD: The influence of preoperative MRI findings on lumbar fusion clinical outcomes. Eur Spine J 21:16161623, 2012

11. Fairbank JC, Couper J, Davies JB, O'Brien JP: The Oswestry low back pain disability questionnaire. Physiotherapy 66: 271-273, 1980

12. Fujiwara A, Lim TH, An HS, Tanaka N, Jeon $\mathrm{CH}$, Andersson $G B$, Haughton VM: The effect of disc degeneration and facet joint osteoarthritis on the segmental flexibility of the lumbar spine. Spine (Phila Pa 1976) 25:3036-3044, 2000

13. Gries NC, Berlemann U, Moore RJ, Vernon-Roberts B: Early histologic changes in lower lumbar discs and facet joints and their correlation. Eur Spine J 9:23-29, 2000

14. Hilibrand AS, Robbins M: Adjacent segment degeneration and adjacent segment disease: The consequence of spinal fusion? Spine J 4:190-194, 2004

15. Kumar S, Sharma VP, Negi MP: Efficacy of dynamic muscular stabilization techniques (DMST) over conventional techniques in rehabilitation of chronic low back pain. J Strength Cond Res 23:2651-2659, 2009
16. López WO, Vialle EN, Anillo CC, Guzmao M, Vialle LR: Clinical and radiological association with positive lumbar discography in patients with chronic low back pain. Evid Based Spine Care J 3:27-34, 2012

17. Mayer HM, Korge A: Non-fusion technology in degenerative lumbar spinal disorders: Facts, questions, challenges. Eur Spine J 11:85-91, 2002

18. Miyakoshi N, Abe E, Shimada Y, Okuyama K, Suzuki T, Sato $\mathrm{K}$ : Outcome of one-level posterior lumbar interbody fusion for spondylolisthesis and postoperative intervertebral disc degeneration adjacent to the fusion. Spine (Phila Pa 1976) 25:1837-1842, 2000

19. Oktenoglu T, Ozer AF, Sasani M, Kaner T, Canbulat N, Ercelen O, Sarioglu AC: Posterior dynamic stabilization in the treatment of lumbar degenerative disc disease: 2-year follow-up. Minim Invasive Neurosurg 53:112-116, 2010

20. Panjabi MM:The stabilizing system of the spine. Part II. Neutral zone and instability hypothesis. J Spinal Disord 5:390-396, 1992

21. Pfirrmann CW, Metzdorf A, Zanetti M, Hodler J, Boos N: Magnetic resonance classification of lumbar intervertebral disc degeneration. Spine (Phila Pa 1976) 26:1873-1878, 2001

22. Reyes-Sánchez A, Zárate-Kalfópulos B, Ramírez-Mora I, Rosales-Olivarez LM, Alpizar-Aguirre A, Sánchez-Bringas G: Posterior dynamic stabilization of the lumbar spine with the Accuflex rod system as a stand-alone device: Experience in 20 patients with 2-year follow-up. Eur Spine J 19:2164-2170, 2010

23. Schmidt TA, An HS, Lim TH, Nowicki BH, Haughton VM: The stiffness of lumbar spinal motion segments with a highintensity zone in the annulus fibrosus. Spine (Phila Pa 1976) 23:2167-2173, 1998

24. Schnake KJ, Putzier M, Haas NP, Kandziora F: Mechanical concepts for disc regeneration. Eur Spine J 15:354-360, 2006

25. Yong-Hing K, Kirkaldy-Willis WH: The pathophysiology of degenerative disease of the lumbar spine. Orthop Clin North Am 14:491-503, 1983

26. Yu SW, Yen CY, Wu CH, Kao FC, Kao YH, Tu YK: Radiographic and clinical results of posterior dynamic stabilization for the treatment of multisegment degenerative disc disease with a minimum follow-up of 3 years. Arch Orthop Trauma Surg 132:583-589, 2012

27. Zagra A, Minoia L, Archetti M, Corriero AS, Ricci K, Teli M, Giudici F: Prospective study of a new dynamic stabilisation system in the treatment of degenerative discopathy and instability of the lumbar spine. Eur Spine J 21:83-89, 2012 